\title{
A Monokine Stimulates Production of Human Erythroid Burst-promoting Activity by Endothelial Cells In Vitro
}

\author{
Kenneth S. Zuckerman, Grover C. Bagby, Jr., Elaine McCall, Betty Sparks, Jackie Wells, Vina Patel, and Danon Goodrum \\ Comprehensive Cancer Center and Division of Hematology and Oncology, University of Alabama in Birmingham, Alabama 35294; \\ Hemopoiesis Research Laboratories, Veterans Administration Medical Center, and E. E. Osgood \\ Memorial Center Laboratory, Oregon Health Sciences University, Portland, Oregon 97201
}

\begin{abstract}
Conditioned media were prepared from human peripheral blood monocytes and human umbilical vein endothelial cells. These media were assayed for erythroid burst-promoting activity (BPA) using human peripheral blood monocyte-depleted mononuclear cells as targets and assessing the stimulatory effect of the conditioned media on growth of early erythroid progenitor cells. Both monocytes and endothelial cells produced modest amounts of detectable BPA. Addition of varying concentrations of media conditioned by monocytes to plateau concentrations (5-10\%) of media conditioned by endothelial cells had no additive effect. Endothelial cells incubated in the presence of $50 \%$ monocyte-conditioned medium produced 2.5 - to 6.6 -fold more BPA than did endothelial cells incubated only in control tissue culture medium. In contrast, endothelial cell conditioned medium did not stimulate increased BPA production by monocytes. Neither neutrophil- nor marrow fibroblastoid cell-conditioned medium stimulated BPA production by endothelial cells. Therefore, both monocytes and endothelial cells produce BPA. Moreover, monocytes produce a monokine that, in turn, stimulates the production of BPA by endothelial cells. Inasmuch as a monokine also has been shown to stimulate production of granulocyte-macrophage colony-stimulating activity, we propose that monocytes play a critical role in regulating the production of humoral regulators of the very early stages of hemopoietic cell differentiation.
\end{abstract}

\section{Introduction}

Erythropoiesis is characterized by an orderly progression of cell differentiation from pluripotent hemopoietic stem cells to unipotent erythroid progenitors (burst-forming units erythroid, BFU-E), ' late erythroid precursors (colony-forming units ery-

Address correspondence to Dr. Zuckerman, 609 Medical Education Building, 1813 6th Ave. South, University of Alabama in Birmingham, AL 35294.

Received for publication 12 July 1983 and in revised form 5 September 1984

1. Abbreviations used in this paper: BFU-E, burst forming units erythroid; BPA, erythroid burst-promoting activity; ECCM, endothelial cell conditioned medium; $\mathrm{ECCM}_{\mathrm{M}}$, conditioned medium from endothelial cells that were incubated in $50 \%$ MCM for $3 \mathrm{~d}$; GM-CSA, granulocyte-macrophage colony stimulating activity; MCM, monocyte conditioned medium; $\mathbf{M C M}_{\mathrm{E}}$, conditioned medium from monocytes that were incubated in 50\% ECCM for $3 \mathrm{~d}$.

J. Clin. Invest.

(c) The American Society for Clinical Investigation, Inc

0021-9738/85/02/0722/04 \$1.00

Volume 75 , February $1985,722-725$ throid), proerythroblasts, hemoglobin containing normoblasts, and finally, mature erythrocytes (1). The mechanisms of regulation of the earliest phases of erythroid differentiation are not known. A material called burst-promoting activity (BPA) has been shown to be a requirement for growth of BFU-E in vitro $(2,3)$. A variety of cells, including monocytes (4-8), macrophages (9), and possibly $T$ lymphocytes (10-12) and endothelial cells (13), have been reported to produce BPA. The means by which BPA production by these cells is regulated is not understood. However, if BPA is produced by several types of cells, and if BPA is a physiologic regulator of the early phases of erythropoiesis, it is necessary to postulate an integrated regulatory system with positive and negative feedback controls. Recent studies have demonstrated that production of another hemopoietic regulator, granulocyte-macrophage colony-stimulating activity (GM-CSA), by a variety of cells is stimulated by a monokine (14-16). The purpose of this study was to determine whether human endothelial cells produce BPA and whether BPA production, like GM-CSA production, could be regulated by a humoral product of monocytes.

\section{Methods}

Preparation of monocyte conditioned medium. Human peripheral blood light density mononuclear cells were obtained by Ficoll-Hypaque density centrifugation (17). T lymphocytes were removed by sheep erythrocyte rosetting and density centrifugation $(5,14)$. The remaining light density, $\mathrm{T}$ cell-depleted mononuclear cells were incubated in serum-coated culture dishes, the nonadherent cells were discarded, and the adherent cells recovered from the dishes after treatment with EDTA (5). The adherent cells were $>90 \% \alpha$-naphthyl butyrate esterase positive and $>90 \%$ viable by trypan blue dye exclusion. These highly enriched monocytes were cultured for $3 \mathrm{~d}$ at $37^{\circ} \mathrm{C}$ in $7.5 \% \mathrm{CO}_{2}$ in air in $60-\mathrm{mm}$ tissue culture dishes at a concentration of $10^{5} \mathrm{cells} / \mathrm{ml}$ in RPMI 1640 medium (Gibco Laboratories, Grand Island, NY) supplemented with $2 \mathrm{mM}$ L-glutamine, $15 \%$ fetal bovine serum, penicillin $50 \mathrm{U} / \mathrm{ml}$, and streptomycin $50 \mu \mathrm{g} / \mathrm{ml}$. Dishes containing culture medium without monocytes served as controls. The monocyte conditioned medium (MCM) was removed from the dishes, filtered, and used fresh or stored at $-20^{\circ} \mathrm{C}$ for future use. In some cases monocytes were incubated for $3 \mathrm{~d}$ in 50\% supplemented RPMI 1640 and $50 \%$ endothelial cell-conditioned medium (ECCM) (see below). The conditioned medium from these monocyte cultures is designated $\mathbf{M C M}_{\mathbf{E}}$.

Preparation of ECCM. Human umbilical vein endothelial cells were prepared as previously described (18), using limited collagenase (type I, $0.1 \% \mathrm{wt} / \mathrm{vol}$ in phosphate-buffered saline; Worthington Diagnostic Systems, Freehold, NJ) treatment. The cells were suspended in RPMI 1640 medium supplemented with $25 \mathrm{mM}$ Hepes buffer, $2 \mathrm{mM}$ L-glutamine, $20 \%$ fetal bovine serum, antibiotics, and $250 \mu \mathrm{g} / \mathrm{ml}$ endothelial cell growth factor (Pel-Freeze Biologicals, Rogers, AR). The endothelial cells were cultured in $16-\mathrm{mm}$ tissue culture wells coated with fibronectin $\left(2 \mu \mathrm{g} / \mathrm{cm}^{2}\right.$ surface area; Collaborative Research, Bethesda, MD) for $3 \mathrm{~d}$ at $37^{\circ} \mathrm{C}$ in $5 \% \mathrm{CO}_{2}$ in air. Both primary and subcultured cells exhibited the "cobblestone" appearance characteristic 
of endothelial cells; and $90-98 \%$ of cells contained Factor VIII-related antigen, as determined by indirect immunofluorescence using rabbit anti-Factor VIII and fluorescein-labeled goat anti-rabbit IgG (Cappel Laboratories, Cochranville, PA). The cells did not exhibit reactivity to monoclonal antibodies reactive with monocytes (OKM-1 or Mac-120) or T lymphocytes (OKT-3), as determined by cytofluorographic analysis. At the end of the culture period, the ECCM was removed from the dishes, filtered, and used fresh or stored frozen at $-20^{\circ} \mathrm{C}$ for future use. In some cases confluent cultures of endothelial cells were incubated in 50\% supplemented RPMI 1640 medium and 50\% MCM for $3 \mathrm{~d}$. The conditioned medium from these cultures is designated $\mathbf{E C C M}_{\mathbf{M}}$. In selected experiments $5,10,25$, or $50 \% \mathrm{MCM}$ was used to determine the optimal stimulatory concentration to use in the preparation of $\mathrm{ECCM}_{\mathbf{M}}$. We also incubated endothelial cells in $50 \%$ medium conditioned for $3 \mathrm{~d}$ by human bone marrow fibroblastoid cells $\left(1-2 \times 10^{5}\right.$ light density adherent marrow cells per milliliter after 3-4 wk in culture) (19). In addition, 50\% media conditioned for $1 \mathrm{~h}, 3 \mathrm{~h}$, or $3 \mathrm{~d}$ by human peripheral blood neutrophils $\left(10^{5} / \mathrm{ml}\right)$ were tested for their ability to stimulate BPA production by endothelial cells.

Assay for human erythroid BPA. Growth of BFU-E derived colonies from human peripheral blood monocyte-depleted mononuclear cells (two consecutive 60- to 90-min adherence procedures in tissue culture dishes) served as our BPA assay system, as described previously (4-7). $10^{5}$ monocyte-depleted mononuclear cells ( $<4 \%$ monocytes, as determined by $\alpha$-naphthyl butyrate esterase and Wright's staining; $>95 \%$ viable by trypan blue dye exclusion) were grown in $0.5-\mathrm{ml}$ plasma clot cultures in the presence of $1 \mathrm{U} / \mathrm{ml}$ erythropoietin (generously provided by the National Heart, Lung and Blood Institute), and varying concentrations of the conditioned media being tested. BPA was assayed by the ability of the conditioned media to increase BFU-E growth in cultures of monocyte-depleted mononuclear cells.

Assay for human GM-CSA. $\mathrm{ECCM}_{\mathrm{M}}$ was assayed for the presence of GM-CSA as described (14-16), using methylcellulose cultures of macrophage-depleted, $T$ cell-depleted, normal human bone marrow mononuclear cells.

Statistical methods. The significance of differences in burst promoting activity in various conditioned media was determined using Student's $t$ test (two-tailed) (20).

\section{Results}

Control cultures containing $10^{5}$ unfractionated mononuclear cells had 44.1 \pm 2.6 detectable BFU-E; whereas in cultures of $10^{5}$ monocyte-depleted mononuclear cells there were $0.7 \pm 0.2$
BFU-E detected (1.6\% of control) (Fig. 1). As shown in Fig. 1 , both monocytes (MCM) and endothelial cells (ECCM) produced BPA, as demonstrated by a significant stimulation of BFU-E growth in cultures containing ECCM or MCM as compared with control cultures of nonadherent mononuclear cells $(P<0.02)$. The BFU-E stimulatory activities found in maximally stimulatory (plateau) concentrations of MCM and ECCM were not additive (see the last two bars in Fig. 1). It was of great interest that monocytes produced a factor or factors that caused a marked enhancement $(P<0.01)$ of BPA production by endothelial cells $\left(\mathrm{ECCM}_{\mathrm{M}}\right)$. However, endothelial cells did not produce any activity that could stimulate BPA production by monocytes (see the bar labeled $\mathrm{MCM}_{\mathrm{E}}$ in Fig. 1). In addition, media conditioned by human peripheral blood neutrophils or by human bone marrow fibroblastoid cells did not stimulate BPA production by endothelial cells (data not shown). Fig. 2 demonstrates that the maximum BFU-E stimulation by MCM, ECCM, and $\mathrm{ECCM}_{\mathrm{M}}$ was observed with 5$10 \%$ final concentrations in the cultures. At each conditioned medium concentration tested, $\mathrm{ECCM}_{\mathrm{M}}$ contained 2.5-fold to 6.6-fold more BPA than did either MCM or ECCM $(P<0.05$ for all concentrations tested except $20 \%$, which was tested only three times). Our monokine dose-response studies demonstrated that peak stimulation of BPA production by endothelial cells occurred when $50 \% \mathrm{MCM}$ was used in preparation of $\mathrm{ECCM}_{\mathbf{M}}$. The lower concentrations of MCM resulted in lower BPA levels produced by endothelial cells as follows: $\mathrm{ECCM}_{\mathrm{M} \text { - }}$ $25 \%, 70 \%$ of peak BPA; ECCM $_{\mathrm{M}-10 \%}, 53 \%$ of peak BPA; $\mathrm{ECCM}_{\mathrm{M}-5 \%}, 47 \%$ of peak BPA.

We evaluated whether the failure of high concentrations of ECCM, MCM, or mixtures of ECCM and MCM to yield as much BPA as $\mathrm{ECCM}_{\mathrm{M}}$ was due to the presence in $\mathrm{MCM}$ or ECCM of inhibitors of BPA production or release. If there were such an inhibitor, the monokine that apparently stimulated endothelial cells to make BPA could actually have worked by inhibiting production of the inhibitor. We carried out a series of mixing studies using varying concentrations ranging from 1 to $20 \% \mathrm{MCM}$ or ECCM added to the optimal concentrations $(5-20 \%)$ of $\mathrm{ECCM}_{\mathrm{M}}$. In no case did we ever detect any
Figure 1. Production of human erythroid BPA by monocytes and endothelial cells. Various conditioned media (CM) were added at a final concentration of $10 \%$, unless otherwise stated, to 0.3-ml plasma clot cultures containing $10^{5}$ nonadherent human peripheral blood mononuclear cells and erythropoietin $1 \mathrm{U} / \mathrm{ml}$. All results are expressed as mean number of BFU-E observed per culture $( \pm \mathrm{SEM})$. The numbers in parentheses represent the numbers of experiments done. The results of control cultures containing $10^{5}$ unfractionated mononuclear cells and no conditioned medium are shown in the first bar. The second bar represents the BFU-E growth in cultures of nonadherent mononuclear cells with no conditioned medium. The remaining bars show the BFU-E growth in cultures containing $10^{5}$ nonadherent mononuclear cells and the various conditioned media. 


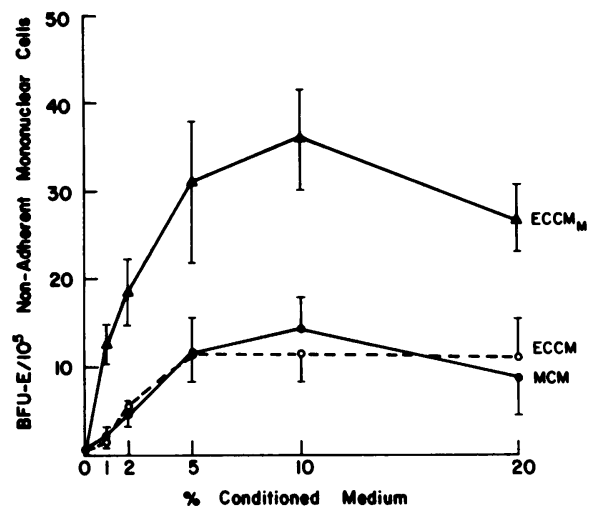

Figure 2. Dose-response curves of human erythroid BPA in media conditioned by MCM, ECCM, or $\mathrm{ECCM}_{\mathrm{M}}$. BPA was assayed by addition of various concentrations of conditioned medium to cultures of $10^{5}$ nonadherent human peripheral blood mononuclear cells. Results are expressed as mean number of BFU-E observed per culture ( \pm SEM). Each datum point represents the mean of five to seven separate experiments.

significant inhibition or further stimulation of the amount of BPA present in the $\mathrm{ECCM}_{M}$ (data not shown).

To confirm that BPA and GM-CSA produced by monokinestimulated endothelial cells were not identical, $\mathrm{ECCM}_{M}$ was heated for $5 \mathrm{~min}$ at 80 or $100^{\circ} \mathrm{C}$. $\mathrm{ECCM}_{\mathrm{M}}$ exposed to 80 or $100^{\circ} \mathrm{C}$ for 5 min contained no detectable GM-CSA. In contrast, boiled $\mathrm{ECCM}_{\mathrm{M}}$ retained $89 \%$ of control BPA, and $\mathrm{ECCM}_{\mathrm{M}}$ heated at $80^{\circ} \mathrm{C}$ for $5 \mathrm{~min}$ had $123 \%$ of control BPA.

\section{Discussion}

We and others have reported previously that monocytes and macrophages are major sources of BPA (4-9). Some groups (10-12) have found normal $T$ lymphocytes to be a source of BPA as well. One group also has reported that human endothelial cells produce BPA (13), although investigators from another laboratory found no significant amount of BPA in endothelial cell conditioned medium (21). In the experiments reported here we again demonstrated production of BPA by unstimulated human peripheral blood monocytes. In addition, we found that confluent cultures of human umbilical vein endothelial cells produce BPA.

If BPA is a physiologic regulator of the early stages of erythropoiesis, production of BPA by cells distributed widely throughout the body would be advantageous. Certainly both monocytes/macrophages and endothelial cells are excellent candidates as cells that could sense and respond to the need for erythroid proliferation and differentiation by producing long range and/or short range stimulators of erythroid progenitors. If both of these cell types can produce BPA, either they respond independently to different stimuli or there is a single regulatory material that in turn stimulates two or even more cell populations to produce BPA.

Recently Bagby et al. (14-16) demonstrated that human monocytes produce a material termed monocyte-derived recruiting activity that is distinct from GM-CSA, but that stimulates production of GM-CSA by endothelial cells, fibroblasts, and $\mathrm{T}$ lymphocytes. The results of our experiments demonstrated that monocytes also produced an activity that stimulated BPA production by endothelial cells. This material in MCM was distinct from BPA, since it augmented BPA production by endothelial cells, but mixtures of plateau levels of MCM and ECCM did not have any additive effects and contained significantly less BPA than did plateau concentrations of $\mathrm{ECCM}_{\mathbf{M}}$. It is clear from our mixing studies that neither MCM nor ECCM contained detectable inhibitors of the BPA found in conditioned medium derived from monokine-stimulated endothelial cells. Furthermore, peak BPA levels were detected in MCM, ECCM, and $\mathrm{ECCM}_{\mathrm{M}}$ at final concentrations of $5-10 \%$ in the BFU-E cultures; and mixtures of MCM and ECCM in final concentrations of $5-10 \%$ of each in the BFU$E$ cultures failed to demonstrate any additive effect. Since $\mathrm{ECCM}_{\mathbf{M}}$ always contained approximately three times the BPA found in plateau concentrations of $\mathrm{MCM}, \mathrm{ECCM}$, or mixtures of MCM and ECCM, it seems that the monokine may have stimulated the production of a distinct BPA-like molecule that was not present in MCM or unstimulated ECCM. The BPA and GM-CSA produced by endothelial cells are different molecules, as demonstrated by the heat resistance of BPA and heat lability of GM-CSA. We do not know yet whether BPAstimulating activity derived from monocytes is distinct from the monokine that stimulates GM-CSA production by other cell populations. However, it is very clear that monocytes play a critical role in regulating both BPA and GM-CSA production.

\section{Acknowledgments}

This work was supported by United States Public Health Service grants AM 27340, AM 33944, and CA 36306, and grants from the Veterans Administration, Jackson Foundation of Oregon, and Leukemia Association of Oregon, Inc.

\section{References}

1. Quesenberry, P., and L. Levitt. 1979. Hematopoietic stem cells. N. Engl. J. Med. 301:755-760, 819-823.

2. Iscove, N. N. 1978. Erythropoietin-independent stimulation of early erythropoiesis in adult marrow cultures by conditioned media from lectin-stimulated mouse spleen cells. In Hematopoietic Cell Proliferation. D. W. Golde, M. J. Cline, D. Metcalf, and C. F. Fox, editors. Academic Press, New York. 37-52.

3. Tsang, R. W., and M. T. Aye. 1979. Evidence for proliferation of erythroid progenitors in the absence of added erythropoietin. Exp. Hematol. 7:383-388.

4. Zuckerman, K. S. 1980. Stimulation of human BFU-E by products of human monocytes and lymphocytes. Exp. Hematol. 8:924932.

5. Zuckerman, K. S. 1981. Human erythroid burst forming units. Growth in vitro is dependent on monocytes, but not on T lymphocytes. J. Clin. Invest. 67:702-709.

6. Zuckerman, K. S., V. R. Patel, and D. D. Goodrum. 1983. Production of human erythroid burst promoting activity by monocytes stimulated with bacterial lipopolysaccharide. Exp. Hematol. 11:475480.

7. Zuckerman, K. S., and M. Haak. 1983. Mitogen-induced stimulation and suppression of erythroid burst promoting activity production by human mononuclear cells. Br. J. Haematol. 55:145-153.

8. Reid, C. D. L., L. C. Baptista, and I. Chanarin. 1981. Erythroid colony growth in vitro from human peripheral blood null cells: evidence of regulation by T-lymphocytes and monocytes. Br. J. Haematol. 48:155-164.

9. Gordon, L. I., W. J. Miller, R. F. Branda, E. D. Zanjani, and H. S. Jacob. 1980. Regulation of erythroid colony formation by bone marrow macrophages. Blood. 55:1047-1050.

10. Nathan, D. G., L. Chess, D. G. Hillman, B. Clarke, J. Breard, 
E. Merler, and D. E. Housman. 1978. Human erythroid burst-forming unit: T cell requirement for proliferation in vitro. J. Exp. Med. 147:324-339.

11. Mangan, K. F., and J. F. Desforges. 1980. The role of $T$ lymphocytes and monocytes in the regulation of human erythropoietic peripheral blood burst-forming units. Exp. Hematol. 8:717-727.

12. Torok-Storb, B., P. J. Martin, and J. A. Hansen. 1981. Regulation of in vitro erythropoiesis by normal $T$ cells: evidence for two T-cell subsets with opposing functions. Blood. 58:171-174.

13. Ascensao, J. L., G. M. Vercellotti, H. S. Jacob, and E. D. Zanjani. 1984. Role of endothelial cells in human hematopoiesis: modulation of mixed colony growth in vitro. Blood. 63:553-558.

14. Bagby, G. C., E. McCall, K. A. Bergstrom, and D. Burger. 1983. A monokine regulates colony-stimulating activity production by vascular endothelial cells. Blood. 62:663-668.

15. Bagby, G. C., E. McCall, and D. L. Layman. 1983. Regulation of colony stimulating activity production. Interactions of fibroblasts, mononuclear phagocytes, and lactoferrin. J. Clin. Invest. 71:340-344.

16. Bagby, G. C., V. D. Rigas, R. M. Bennett, A. A. Vandenbark, and H. S. Garewall. 1981. Interaction of lactoferrin, monocytes, and
T-lymphocyte subsets in the regulation of steady-state granulopoiesis in vitro. J. Clin. Invest. 68:56-63.

17. Boyum; A. 1968. Isolation of mononuclear cells and granulocytes from human blood. Scand. J. Clin. Lab. Invest. 21(Suppl. 97):77-109.

18. Quesenberry, P. J., and M. A. Gimbrone, Jr. 1980. Vascular endothelium as a regulator of granulopoiesis: production of colonystimulating activity by cultured human endothelial cells. Blood. 56:10601067.

19. Broudy, V., K. Zuckerman, S. Jetmalani, J. Fitchen, and G. C. Bagby. 1984. The production of burst promoting activity (BPA) and colony stimulating activity (CSA) by adherent fibroblastoid marrow cells (F) is regulated by autologous monocytes. Clin. Res. 32:305A. (Abstr.)

20. Brown, B. W., Jr., and M. Hollander. 1977. Statistics: a Biomedical İtroduction. John Wiley and Sons, New York, 109-121.

21. Gordon, M. Y., L. Kearney, and J. A. Hibbin. 1983. Effects of human marrow stromal cells on proliferation by human granulocytes (GM-CFC), erythroid (BFU-E) and mixed (Mix-CFC) colony-forming cells. Br. J. Haematol. 53:317-325. 